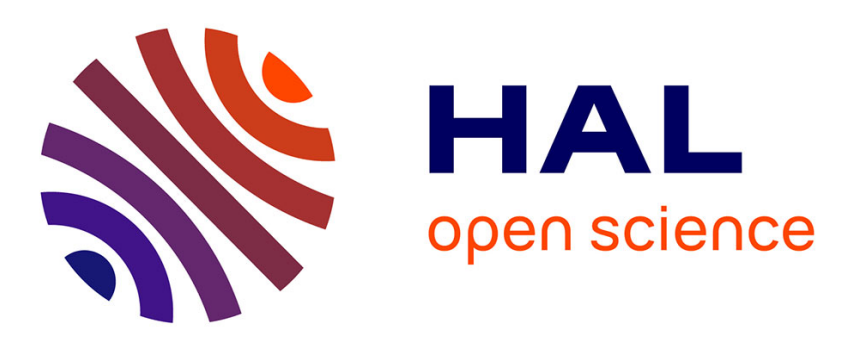

\title{
Iodine(III)-Mediated Umpolung of Bromide Salts for the Ethoxybromination of Enamides.
}

Sophie Nocquet-Thibault, Pascal Retailleau, Kevin Cariou, Robert H Dodd

\section{To cite this version:}

Sophie Nocquet-Thibault, Pascal Retailleau, Kevin Cariou, Robert H Dodd. Iodine(III)-Mediated Umpolung of Bromide Salts for the Ethoxybromination of Enamides.. Organic Letters, 2013, 15 (8), pp.1842-5. 10.1021/ol400453b . hal-00827755

\section{HAL Id: hal-00827755 \\ https://hal.science/hal-00827755}

Submitted on 25 Nov 2020

HAL is a multi-disciplinary open access archive for the deposit and dissemination of scientific research documents, whether they are published or not. The documents may come from teaching and research institutions in France or abroad, or from public or private research centers.
L'archive ouverte pluridisciplinaire HAL, est destinée au dépôt et à la diffusion de documents scientifiques de niveau recherche, publiés ou non, émanant des établissements d'enseignement et de recherche français ou étrangers, des laboratoires publics ou privés. 


\title{
lodine(III)-Mediated Umpolung of Bromide Salts for the Ethoxybromination of Enamides
}

\author{
Sophie Nocquet-Thibault, Pascal Retailleau, ${ }^{\dagger}$ Kevin Cariou and \\ Robert H. Dodd*
}

Centre de Recherche de Gif-sur-Yvette, Institut de Chimie des Substances Naturelles, CNRS, 91198 Gif-sur-Yvette Cedex, France robert.dodd@icsn.cnrs-gif.fr

Received Date (will be automatically inserted after manuscript is accepted)

\section{ABSTRACT}

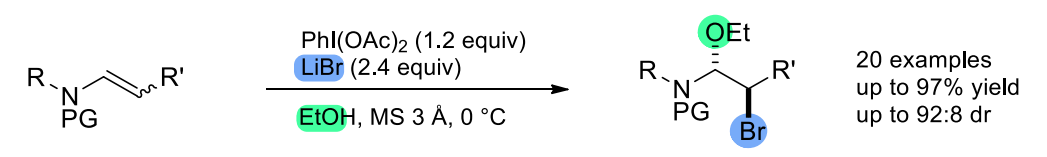

Using (diacetoxyiodo)benzene in conjunction with simple bromide salts in ethanol allows the regioselective ethoxybromination of a wide range of enamides, thus yielding highly versatile $\alpha$-bromo hemiaminals, which can then be engaged in a broad array of transformations.

In recent years, polyvalent iodine compounds have been at the center of tremendous activity and research developments. $^{1}$ Of special interest are iodine(III) compounds such as Koser's reagent ${ }^{2}$ and (diacetoxyiodo)benzene (PIDA). ${ }^{1,2}$ One of the particular characteristics of these compounds is that they behave in a similar fashion to transition-metal complexes. ${ }^{3}$ Indeed, around the central iodine atom, ligands can be exchanged and then transferred through a formal reductive elimination. In this context, halides can be used as ligands, in which case an umpolung of the salt ${ }^{4}$ can occur to give birth to electrophilic halogen species. Several combinations of alkali or metal halide salts and hypervalent iodine(III) derivatives have previously been

${ }^{1}$ (a) Brown, M.; Farid, U.; Wirth, T. Synlett 2013, 424. (b) Zhdankin, V. V.; Stang, P. J. Chem. Rev. 2008, 108, 5299. (c) Wirth, T. Angew. Chem., Int. Ed. 2005, 44, 3656. (d) Zhdankin, V. V.; Stang, P. J. Chem. Rev. 2002, 102, 2523. (e) Varvoglis, A. Tetrahedron 1997, 53, 1179. (f) Stang, P. J.; Zhdankin, V. V. Chem. Rev. 1996, 96, 1123.

${ }^{2}$ Koser, G. F. Aldrichimica Acta 2001, 34, 89.

${ }^{3}$ Moriarty R. M. J. Org. Chem. 2005, 70, 2893.

${ }^{4}$ For another strategy using sulfoxides, see: Klimczyk, S.; Huang, X.; Farès, C.; Maulide, N. Org. Biomol. Chem. 2012, 10, 4327.

${ }^{5}$ (a) Liu W. L.; Chen, C.; Zhang, Q.; Zhu Z.-B. Beilstein J. Org. Chem. 2012, 8, 344. (b) Lee, J. C.; Park, J. Y.; Yoon, S. Y.; Bae, Y. H.; Lee, S. J. Tetrahedron Lett. 2004, 45, 191. (c) Akula, R.; Galligan, M. Ibrahim, H. Chem. Commun. 2009, 45, 6991. (d) Coats, S. J.; Wasserman, H. H. Tetrahedron Lett. 1995, 36, 7735 .

${ }^{6}$ (a) Tu, D.; Ma, L.; Tong, X.; Deng, X.; Xia, C. Org. Lett. 2012, 14, 4830. (b) Hamamoto, H.; Hattori, S.; Takemaru, K.; Miki Y. Synlett. 2011, 1563. (c) Hamamoto, H.; Umemoto, H.; Umemoto, M.; Ohta, C.; Dohshita, M.; Miki Y. Synlett 2010, 2593. (d) Braddock, D. C.; Cansell, G.; Hermitage, S. A. Synlett 2004, 461. studied and reacted with substrates such as carbonyls, ${ }^{5}$ electron-rich arenes, ${ }^{6}$ olefins, ${ }^{7}$ and even aliphatic $\mathrm{CH}$ bonds. $^{8}$

We have recently explored the reactivity of enamides $\mathbf{1}$ toward nitrenoids generated from iodine(III) species, namely iminoiodanes, in the presence of a nucleophile..$^{9 a}$ This set of reaction conditions allowed the oxidative difunctionalization of the enamide to give the corresponding amino hemiaminal in a completely regioand stereoselective manner (Scheme 1, eq 1).

${ }^{7}$ (a) Fabry, D. C.; Stodulski, M.; Hoerner, S.;Gulder, T. Chem-Eur. J 2012, 18, 10834. (b) Pandit, P.; Gayen, K. S.; Khamarui, S.; Chatterjee, N.; Maiti, D. K. Chem. Commun. 2011, 47, 6933. (c) Yu, L.; Ren, L.; Yi, R.; Wu, Y.; Chen, T.; Guo, R. Synlett 2011, 579. (d) Sanjaya, S.; Chiba, S. Tetrahedron 2011, 67, 590. (e) Katrun, P.; Chiampanichayakul, S.; Korworapan, K.; Pohmakotr, M.; Reutrakul, V.; Jaipetch, T.; Kuhakarn C. Eur. J. Org. Chem. 2010, 5633. (f) Wu, T.; Yin, G.; Liu, G. J. Am. Chem. Soc. 2009, 131, 16355. (g) Fan, R.; Wen, F.; Qin, L.; Pu, D.; Wang, B. Tetrahedron Lett. 2007, 48, 7444. (h) Liu, H.; Tan C.-H. Tetrahedron Lett. 2007, 48, 8220. (i) Emmanuvel, L.; Shaikh, T. M. A.; Sudala, A. Org. Lett. 2005, 7, 5071. (j) Braddock, D. C.; Cansell, G.; Hermitage, S. A. Synlett 2004, 461. (k) Hashem, M. A.; Jung, A.; Ries, M.; Kirschning, A. Synlett 1998, 195.

8 (a) McMurtrey, K. B.; Racowski, J. M.; Sanford, M. S. Org. Lett. 2012, 14, 4094. (b) Dohi, T.; Takenaga, N.; Goto, A.; Maruyama, A.; Kita, Y. Org. Lett. 2007, 9, 3129.

${ }^{9}$ (a) Nakanishi, M.; Minard, C.; Cariou, K.; Retailleau, P.; Dodd, R. H. Org. Lett. 2011, 13, 5792. (b) For a related reaction using Rh catalysts, see: Gigant, N.; Dequirez, G.; Retailleau, P.; Gillaizeau, I.; Dauban, P. Chem-Eur. J. 2012, 18, 90. 
Extrapolating from this, we reasoned that subjecting the same type of enamide to a combination of a halide source and iodobenzene diacetate, ${ }^{10}$ we could in turn

Scheme 1. Initial Endeavor
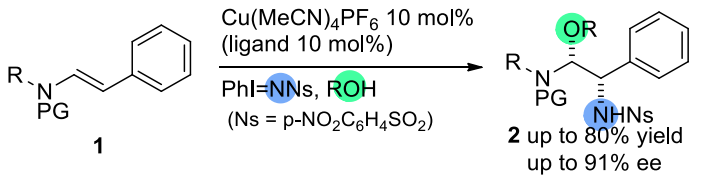

eq 1
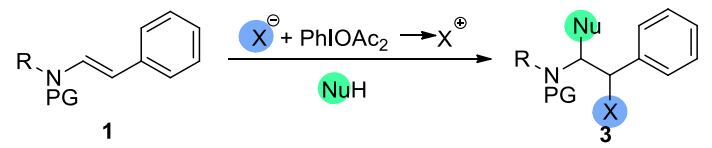

eq 2

obtain an $\alpha$-bromo hemiaminal, which would constitute a highly versatile synthon for further transformations (Scheme 1, eq 2). ${ }^{11}$

Moreover, the low toxicity of iodine(III) derivatives ${ }^{1}$ and their potential for asymmetric transformations ${ }^{12}$ led us to consider that this strategy would provide a valuable alternative to the use of anodic oxidation of bromides, ${ }^{13}$ toxic bromine, ${ }^{14}$ or NBS, ${ }^{15}$ which furthermore, have so far been mostly limited to cyclic enamide derivatives. ${ }^{16}$

We started by reacting tosyl enamide 1a with an excess of iodobenzene diacetate in the presence of a 2 -fold amount of lithium bromide in dry acetonitrile. The lithium salt was chosen because, as an alkali halide, it is cheap and widely available and also exhibits a better solubility than other alkali salts in organic solvents. Under these conditions, there is no external nucleophile other than the acetate, which is liberated by reaction of the iodobenzene diacetate and is regioselectively incorporated in the final product (Table 1, entry 1). However, this product could only be isolated in moderate yield (as a mixture of two diastereoisomers in a 4:1 ratio) because of the low stability of the acetoxy hemiaminal moiety.

Table 1. Optimization of Reaction Conditions

10 For metal-free reactions involving enamides and (diacyloxyiodo)benzenes, see: (a) Zhao, F.; Liu, X.; Qi, R.; ZhangNegrerie, D.; Huang, J.; Du, Y.; Zhao, K. J. Org. Chem. 2011, 76, 10338. (b) Yu, W.; Du, Y.; Zhao, K. Org. Lett. 2009, 11, 2417. (c) Huang, X.; Shao, N.; Huryk, R.; Palani, A.; Aslanian, R.; Seidel-Dugan, C. Org. Lett. 2009, 11, 867. (d) Shao, N.; Huang, X.; Palani, A.; Aslanian, R.; Buevich, A.; Piwinski, J.; Huryk, R.; Seidel-Dugan, C. Synthesis 2009, 2855. (e) Huang, X.; Shao, N.; Palani, A.; Aslanian, R.; Buevich, A. Org. Lett. 2007, 9, 2597. (f) Huang, X.; Shao, N.; Palani, A.; Aslanian, R Tetrahedron Lett. 2007, 48, 1967.

${ }^{11}$ An illustration of this versatility, for cyclic $\alpha$-iodo-hemiaminals, can be found in: (a) Norton Matos, M. R. P.; Afonso, C. A.; Batey, R. A Tetrahedron 2001, 61, 1221. (b) Norton Matos, M. R. P.; Afonso, C. A. M.; McGarvey, T.;Lee, P.; Batey, R. A. Tetrahedron Lett. 1999, 40, 9189.

${ }_{12}$ (a) Farid, U.; Wirth, T. In Asymmetric Synthesis II; Christmann, M., Bräse, S., Eds.; Wiley-VCH: Weinheim, 2012; pp 197 - 203. (b) Liang,

\begin{tabular}{|c|c|c|c|c|c|c|}
\hline 1 & & & $\begin{array}{l}(\mathrm{OAc})_{2} \\
\text { vent, } 3\end{array}$ & $\begin{array}{l}\text { S equiv } \\
\text { MS, temp, }\end{array}$ & $\mathrm{Ph}_{-\mathrm{N}}$ & $\mathrm{Br}$ \\
\hline entry & $\mathrm{X}$ & solvent & $\begin{array}{l}\text { Temp } \\
\left({ }^{\circ} \mathrm{C}\right)\end{array}$ & $t(\min )$ & misc & $\begin{array}{l}\mathrm{R}, \\
\text { yield }^{a} \\
(\%)\end{array}$ \\
\hline 1 & 1.8 & $\mathrm{MeCN}$ & $\mathrm{rt}$ & 70 & no MS & Ac, 59 \\
\hline 2 & 1.4 & $\mathrm{MeCN}$ & $\mathrm{rt}$ & 10 & MS & Ac, 72 \\
\hline 3 & 1.4 & $\mathrm{MeCN}$ & $\mathrm{rt}$ & 10 & $\begin{array}{l}5 \text { equiv of } \\
\text { EtOH }\end{array}$ & Et, $85^{b}$ \\
\hline 4 & 1.4 & $\mathrm{MeCN}$ & $\mathrm{rt}$ & 10 & $\begin{array}{l}10 \text { equiv } \\
\text { of EtOH }\end{array}$ & Et, $95^{c}$ \\
\hline 5 & 1.4 & EtOH & $\mathrm{rt}$ & 10 & $\mathrm{dr} 80 / 20$ & $\mathrm{Et}, 100^{d}$ \\
\hline 6 & 1.4 & EtOH & 0 & 20 & dr $83 / 17$ & Et, 91 \\
\hline 7 & 1.1 & $\mathrm{EtOH}$ & 0 & 90 & $e$ & Et, 86 \\
\hline 8 & 1.2 & EtOH & 0 & 25 & dr 87/13 & Et, 97 \\
\hline 9 & 1.2 & $\mathrm{EtOH}$ & -20 & $20 \mathrm{~h}$ & dr $88 / 12$ & Et, $100^{d}$ \\
\hline
\end{tabular}

${ }^{a}$ Isolated yields after chromatography on silica gel unless otherwise mentioned. ${ }^{b}$ Conversion determined by ${ }^{1} \mathrm{HNMR}$, along with $15 \%$ of $\mathrm{R}=$ Ac. ${ }^{c}$ Conversion determined by ${ }^{1} \mathrm{H}$ NMR, along with $5 \%$ of $\mathrm{R}=$ Ac. ${ }^{\mathrm{d}}$ Conversion determined by ${ }^{1} \mathrm{H} \mathrm{NMR} ;{ }^{e} 10 \mathrm{~mol} \%$ of PIDA and $20 \mathrm{~mol} \%$ of $\mathrm{LiBr}$ were added after $60 \mathrm{~min}$.

Adding molecular sieves to the reaction mixture allowed shorter reaction times while improving the yield to some extent (entry 2), but the stability of the adduct remained an issue. Assuming this problem was due to the acetoxy group, ethanol was added as an external nucleophile but competitive addition of the acetate was still observed (entries 3 and 4). Finally, complete chemoselectivity in favor of ethoxy products was obtained by using ethanol as the solvent (entry 5). Lowering the temperature to $0{ }^{\circ} \mathrm{C}$ increased the diastereoselectivity, and the optimal amount of reagents was found to be 1.2 equiv of PIDA and 2.4 equiv of lithium bromide, which efficiently provided $97 \%$ of the desired product 3a with a 87:13 diastereomeric ratio (entries 6-8). Diminishing the temperature further to -20 ${ }^{\circ} \mathrm{C}$ only increased the reaction time without any real improvement of the diastereoselectivity (entry 9). The relative configuration of the major diastereoisomer was

H.; Ciufolini M. A. Angew. Chem. Int. Ed. 2011, 50, 11849. (c) Uyanik, M.; Okamoto, H.; Yasui, T.; Ishihara, K. Science 2010, 328, 1376.

13 (a) Shono, T.; Matsumura, Y.; Onomura, O.; Ogaki, M.; Kanazawa, T. J. Org. Chem. 1987, 52, 536. (b) Shono, T.; Matsumura, Y.; Ogaki, M.; Onomura, O. Chem. Lett. 1987, 1447.

14 (a) Kelleher, S.; Quesne, P.-Y.; Evans P. Beilstein J. Org. Chem. 2009, 10.3762/bjoc.5.69. (b) Sugiura, M.; Asai, K.; Hamada, Y.; Hatano, K.; Kurono, Y.; Suezawa, H.; Hirota, M. Chem. Pharm. Bull. 1997, 45, 928. (c) Shono, T.; Matsumura, Y.; Onomura, O.; Yanada, Y. Tetrahedron Lett. 1987, 28, 4073.

15 (a) Le Corre, L.; Kizirian, J.-C.; Levraud, C.; Boucher, J.-L.; Bonnet, V.; Dhimane, H. Org. Biomol. Chem. 2008, 6, 3388. (b) Levraud, C.; Calvet-Vitale, S.; Bertho, G.; Dhimane, H. Eur. J. Org. Chem. 2008, 1901.

${ }^{16}$ For acyclic enamines, see: (a) Alix, A.; Lalli, C.; Retailleau, P.; Masson G. J. Am. Chem. Soc. 2012, 134, 10389. (b) Jokić, M.; Škarić, V. Tetrahedron Lett. 1994, 35, 2937. 
attributed from the X-ray data obtained for ethoxy-3a (Figure 1) which was further confirmed from the X-ray data obtained for compound $\mathbf{3 p}$ (see Table 2).
Figure 1. ORTEP drawings for OEt-3a and 3p.
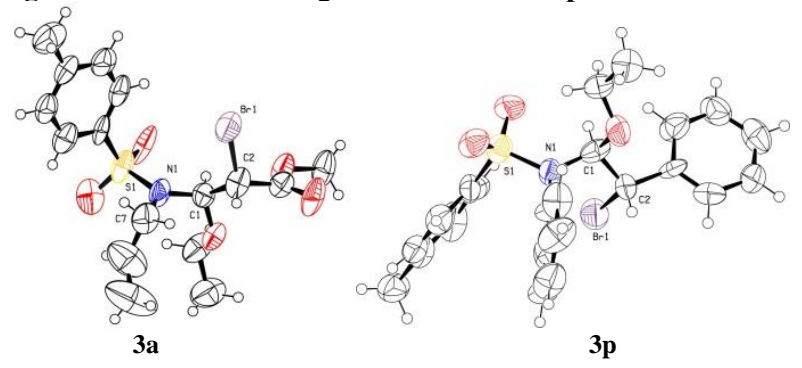

First, varying the sulfonamide protecting group had only a small influence on the course of the reaction (Table 2, 1ad) though the tosyl group was the most satisfying in terms of yield and diastereoselectivity. The slight variations in the diastereoisomeric ratio are consistent with steric effects, while the more electron-withdrawing nosyl group only caused a moderate loss in efficiency. Moreover, comparison between the ${ }^{1} \mathrm{H}$ NMR spectra of the various $\alpha$ bromo hemiaminals obtained and 3a showed that the major diastereoisomer was the same in all cases. Replacement of the phenyl by a $p$-methoxyphenyl, a benzyl, an allyl, or a methyl group (1- $\mathbf{e}-\mathbf{h})$, led to incremental improvements of the dr, probably due to subtle variations of the steric hindrance. It is noteworthy that this reaction proved to be highly chemoselective, as neither the electron-rich anisyl ${ }^{6}$ (1e) nor the allyl ${ }^{7}(\mathbf{1 g})$ moieties were affected in this transformation. On the other hand, switching from a sulfonamide to an amide or a carbamate proved highly detrimental. Indeed, when submitted to the reaction conditions $\mathrm{N}$-Ac compounds only gave a complex mixture $(\mathbf{1} \mathbf{i}, \mathbf{j})$. This phenomenon was slightly less pronounced for $\mathrm{N}$-Boc substrates, in which case the formation of the desired product could be observed before it decomposed $(\mathbf{1 k}, \mathbf{l})$. When differently functionalized substrates such as (E)-2-aminoacrylates were subjected to the same reaction conditions $(\mathbf{1} \mathbf{m}-\mathbf{p})$, the $\mathrm{dr}$ were consistently above the 90/10 threshold (as observed for the crude material, the adducts were often isolated as a single diastereoisomer) and the yields remained excellent, with the major isomer corresponding to that obtained for $(E)$-2-aminostyrenes (as evidenced by the X-ray analysis of $\mathbf{3 p}$, Figure 1). In contrast, the $Z$ isomers gave the desired product in lower yields and with almost no diastereoselectivity (1q,,r). Finally, it should be noted that, despite the oxidative nature of the reaction conditions, free alcohols are tolerated and give the corresponding adducts with moderate yields but excellent diastereoselectivities $(\mathbf{1} \mathbf{s}, \mathbf{t})$.

${ }^{17} \mathrm{dr}$ were calculated using ${ }^{1} \mathrm{H}$ NMR analysis of the crude material. The slightly higher values reported in the Supporting Information correspond to isolated products.
Table 2. Substrate Scope for the Ethoxybromination ${ }^{17}$

\begin{tabular}{|c|c|c|c|c|c|c|}
\hline & ${ }_{1 \text { a-t }}$ & & $\begin{array}{l}\mathrm{Phl}(\mathrm{OAc})_{2}(1.2 \mathrm{e} \\
\mathrm{LiBr}(2.4 \text { equiv) } \\
\text { EtOH, MS } 3 \AA, 0\end{array}$ & & ${ }_{P G}^{N}{ }_{P}^{N}$ & \\
\hline s.m. & $\mathrm{R}$ & PG & $\mathrm{R}^{\prime}$ & $t(\min )$ & $\mathrm{dr}^{a}$ & $\begin{array}{l}\text { yield }^{b} \\
(\%)\end{array}$ \\
\hline $1 \mathbf{a}$ & $\mathrm{Ph}$ & Ts & $\mathrm{Ph}(E)$ & 25 & $87 / 13$ & 97 \\
\hline $1 b$ & $\mathrm{Ph}$ & $\mathrm{PhSO}_{2}$ & $\mathrm{Ph}(E)$ & 30 & $83 / 17$ & 88 \\
\hline $1 \mathrm{c}$ & $\mathrm{Ph}$ & Ms & $\mathrm{Ph}(E)$ & 40 & $76 / 24$ & 89 \\
\hline 1d & $\mathrm{Ph}$ & Ns & $\mathrm{Ph}(E)$ & 25 & $92 / 8$ & $81^{c}$ \\
\hline 1e & PMP & Ts & $\mathrm{Ph}(E)$ & 60 & $77 / 23$ & $71^{d}$ \\
\hline 1f & $\mathrm{Bn}$ & Ts & $\mathrm{Ph}(E)$ & 20 & $83 / 17$ & $88^{c}$ \\
\hline $1 \mathrm{~g}$ & Allyl & Ts & $\mathrm{Ph}(E)$ & 50 & $90 / 10$ & 89 \\
\hline $1 \mathrm{~h}$ & $\mathrm{Me}$ & $\mathrm{PhSO}_{2}$ & $\mathrm{Ph}(E)$ & 20 & $92 / 8$ & 89 \\
\hline $1 \mathbf{i}$ & $\mathrm{Ph}$ & Ac & $\mathrm{Ph}(E)$ & 50 & N.D. & c.m. \\
\hline $1 \mathrm{j}$ & $\mathrm{Bn}$ & Ac & $\mathrm{Ph}(E)$ & 40 & N.D. & c.m. \\
\hline $1 \mathrm{k}$ & $\mathrm{Ph}$ & Boc & $\mathrm{Ph}(E)$ & 30 & $79 / 21$ & $49^{e}$ \\
\hline 11 & $\mathrm{Bn}$ & Boc & $\mathrm{Ph}(E)$ & 45 & $71 / 29$ & N.D. \\
\hline $1 \mathrm{~m}$ & PMP & Ts & $\mathrm{CO}_{2} \mathrm{Me}(E)$ & 120 & $92 / 8$ & $79^{e}$ \\
\hline 1n & $\mathrm{Bn}$ & Ts & $\mathrm{CO}_{2} \mathrm{Me}(E)$ & 150 & $92 / 8$ & $73^{e}$ \\
\hline 10 & $\mathrm{Bn}$ & Ns & $\mathrm{CO}_{2} \mathrm{Me}(E)$ & 90 & $92 / 8$ & $55^{e}$ \\
\hline $1 p$ & Allyl & Ts & $\mathrm{CO}_{2} \mathrm{Me}(E)$ & 40 & $91 / 9$ & 74 \\
\hline $1 q$ & $\mathrm{Bn}$ & Ts & $\mathrm{CO}_{2} \mathrm{Me}(Z)$ & 60 & $52 / 48$ & 52 \\
\hline $1 \mathbf{r}$ & Allyl & Ts & $\mathrm{CO}_{2} \mathrm{Me}(Z)$ & 45 & $55 / 45$ & 65 \\
\hline $1 \mathrm{~s}$ & $\mathrm{Bn}$ & Ts & $\mathrm{CH}_{2} \mathrm{OH}(E)$ & 30 & $92 / 8$ & $60^{e f f}$ \\
\hline $1 t$ & Allyl & Ts & $\mathrm{CH}_{2} \mathrm{OH}(E)$ & 90 & $92 / 8$ & $46^{f}$ \\
\hline
\end{tabular}

${ }^{a}$ Calculated by ${ }^{1} \mathrm{H}$ NMR analysis of the crude material. N.D. $=$ not determined. ${ }^{b}$ Isolated yields after chromatography on silica gel. c.m. $=$ complex mixture. ${ }^{c}$ Reaction run with 1.4 equiv. of PIDA and 2.8 equiv. of LiBr. ${ }^{d} 10 \mathrm{~mol} \%$ of PIDA and $20 \mathrm{~mol} \%$ of $\mathrm{LiBr}$ were added after 30 min. ${ }^{e}$ Isolated as a single diastereoisomer. ${ }^{f}$ Reaction run with 1.2 equiv of PIDA and 4.5 equiv of $\mathrm{LiBr}$ on a $1 \mathrm{mmol}$ scale.

The strong discrepancy observed between the reactivity of the $E$ and $Z$ isomers raised a few questions concerning the mechanism of this transformation. First, at this stage, the exact nature of the electrophile remains conjectural. In the presence of bromide ions a series of equilibria could take place between iodobenzene diacetate and iodobenzene dibromide 5 through the mixed species $\mathbf{4}$ (Scheme 2)..$^{5-8,18}$ For both in situ generated iodine(III)

\footnotetext{
${ }^{18}$ For the isolation and characterization of such compounds, see: (a) Braddock, D. C.; Cansell, G.; Hermitage, S. A.; White, A. J. P. Chem.
} 
reagents a reductive elimination can take place, producing acetyl hypobromite or bromine. Formally, all four species can be considered as $\mathrm{Br}^{+}$sources for the reaction.

We then assume that the reaction between the enamide 1 and the electrophilic bromonium species (whatever its exact nature) would stereospecifically lead to bridged bromonium 6, which would be in equilibrium with iminium 7 (Scheme 3).

Scheme 2. Generation of the Electrophilic Species

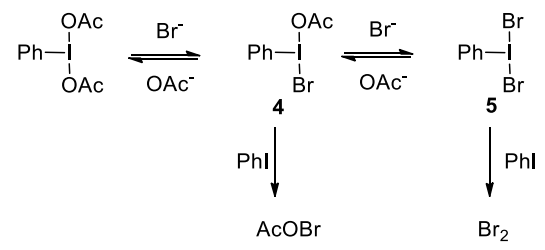

Depending on the various stereoelectronic effects at play, one form might be favored over the other, thus influencing the final diastereoselective ratio as the addition of the external nucleophile (ethanol) would proceed through an $\mathrm{S}_{\mathrm{N}} 2$ and/or $\mathrm{S}_{\mathrm{N}} 1$ type mechanism. Indeed, (Z)enamide would give rise to cis-6 in which unfavorable 1,2 steric interaction would displace the equilibrium toward the iminium and therefore cause a drastic lowering of the diastereoselectivity (as was observed for substrates 1q,r). Lastly, it should be pointed out that the X-ray data for the major stereoisomer (both for $\mathrm{R}^{\prime}=\mathrm{Ph}, \mathbf{3 a}$ and for $\mathrm{R}^{\prime}=$ $\mathrm{CO}_{2} \mathrm{Me}, 3 \mathbf{p}$ ) are consistent with an $\mathrm{S}_{\mathrm{N}} 2$-type opening of bromonium trans-6a by ethanol.

Scheme 3. Mechanistic Proposal

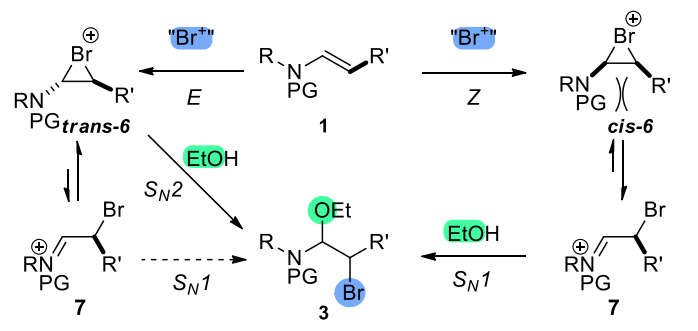

As already stated, these $\alpha$-bromo hemiaminals are highly versatile synthons, and so we went on to probe their behavior in several transformations. First, using a Lewis acid such as boron trifluoride etherate allows the regeneration of iminium 7 (and putatively bromonium 6) and the subsequent addition of soft nucleophiles such as triethylsilane and allyltrimethylsilane (Scheme 4). Both reduction and allylation proceed smoothly to give $\alpha$-bromo

Commun. 2006, 1442. (b) Amey, R. L.; Martin, J. C. J. Org. Chem. 1979, 44,1779 . amines (8 and $\mathbf{9}$ ) in moderate to good yields (unoptimized) and as a single diastereomer for $\mathbf{9 a}$ and $\mathbf{9 b}$. Diallylic compound 9b could be elaborated further by Grubbs' second-generation catalyst-triggered ring-closing metathesis, which yielded the corresponding tetrahydropyridine $\mathbf{1 0}$ quantitatively. The bromo moiety could also be exploited. Simple treatment of the free alcohols $\mathbf{3 s}$ and $\mathbf{3 t}$ with sodium hydroxide cleanly afforded $\alpha$-amino epoxides $11 \mathbf{a}$ and $\mathbf{1 1 b}$. $N$-Allyl substrate $8 \mathrm{~b}$ could be cyclized under either palladium-catalyzed ${ }^{19}$ or radicalinitiated conditions to give two types of substituted pyrrolidines 12 and 13 , respectively.

Scheme 4. Exploiting the Versatility of the Adducts ${ }^{a}$

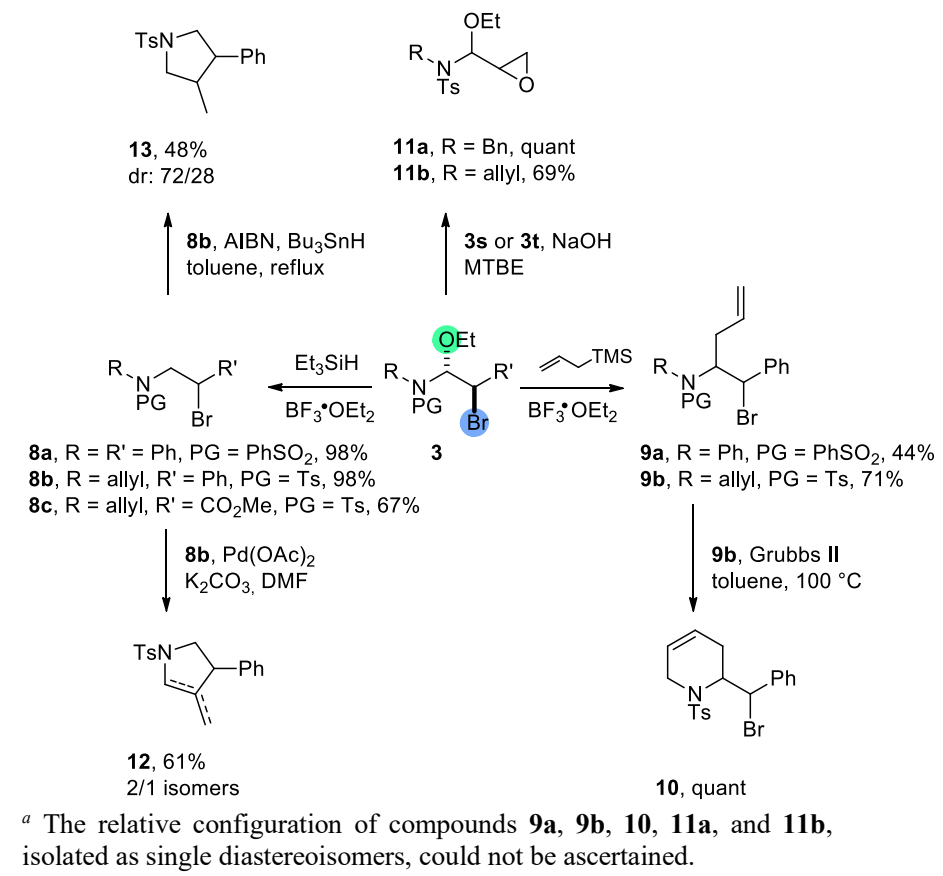

In summary, using a combination of PIDA and lithium bromide in ethanol enabled the regioselective alkoxybromination of variously substituted enamide derivatives with excellent yield and selectivity. The resulting $\alpha$-bromo hemiaminals could then be elaborated further using various strategies ranging from radical to transition-metal-catalyzed transformations. Efforts toward the development of an asymmetric variant of this transformation and its use for the synthesis of biologically relevant targets are currently underway in our laboratory.

Acknowledgment. We thank the Institut de Chimie des Substances Naturelles for financial support and fellowship for S. N.-T.. We also thank Dr. Géraldine Masson (ICSN) for helpful discussions.

${ }^{19}$ Zhou, W.; An, G.; Zhang, G.; Han, J.; Pan, Y. Org. Biomol. Chem., 2011, 9, 5833. In this paper, the authors report the formation of the sole endo isomer with $86 \%$ yield from the same starting compound. 
Supporting Information Available. Experimental procedures and characterization of compounds. This material is available free of charge via the Internet at http://pubs.acs.org.). ${ }^{20}$ 